\title{
Construction of mutants of Actinobacillus actinomycetemcomitans defective in serotype b-specific polysaccharide antigen by insertion of transposon Tn916
}

\author{
Setsuko Sato, ${ }^{1}$ Nobumi Takamatsu, ${ }^{1}$ Nobuo OKahashi, ${ }^{1}$ Nobuko Matsunoshita, ${ }^{2}$ \\ MASAKaZU INOUE, ${ }^{2}$ TADAMICHI TAKEHARA ${ }^{3}$ and TOSHIHIKo $\mathrm{KOGA}^{1 *}$ \\ 'Department of Dental Research, National Institute of Health, Kamiosaki, Shinagawa-ku, Tokyo 141, Japan \\ ${ }^{2}$ Department of Preventive Dentistry, Kagoshima University Dental School, Sakuragaoka, Kagoshima 890, Japan \\ ${ }^{3}$ Department of Preventive Dentistry, Kyushu Dental College, Kokurakitaku, Kitakyushu 803, Japan
}

(Received 5 November 1991; revised 14 January 1992; accepted 24 February 1992)

\begin{abstract}
Mutants of Actinobacillus actinomycetemcomitans strain Y4 defective in the capsular-like serotype b-specific polysaccharide antigen (SPA) were constructed by inserting the transposon Tn916. Southern blot analysis suggested that the transposon was inserted into a variety of different sites on the chromosome. Whole cells from two mutants (strains ST1 and ST2) lacked reactivity with a monoclonal antibody to SPA of $A$. actinomycetemcomitans Y4 (mAb S5) in enzyme-linked immunosorbent assay, but those from another nine mutants (e.g. strains ST3 and ST5) reacted very weakly with mAb S5. Immunodiffusion tests showed that mAb S5 or rabbit antiserum against whole cells of strain Y4 produced a fused precipitin band with purified SPA and autoclaved extract from strain Y4, but no precipitin band with autoclaved extracts from these four mutants. The hydrolysate of autoclaved extract from strain Y4 contained equal amounts of rhamnose and fucose, component sugars of SPA. The hydrolysates of autoclaved extracts from strains ST1 and ST2 contained a trace amount of rhamnose, but not fucose. Those of autoclaved extracts from strains ST3 and ST5 contained a trace amount of fucose, but not rhamnose. All of these SPA-defective mutants reacted with a mAb to lipopolysaccharide of strain Y4. The cell hydrophobicity of SPA-defective mutants was higher than that of the parent strain. These mutant clones will be useful for analysing the gene complex responsible for the synthesis of SPA of $A$. actinomycetemcomitans and the regulation of expression of the polysaccharide.
\end{abstract}

\section{Introduction}

Actinobacillus actinomycetemcomitans is associated with localized juvenile periodontitis and adult periodontitis (Tanner et al., 1979; Slots \& Genco, 1984; Slots \& Schonfeld, 1991). The organisms are serologically classified into three serotypes, a, b and c (Zambon et al., 1983). In subjects with periodontal disease, serotype $b$ is the most frequently isolated (Zambon et al., 1983; Asikainen et al., 1991). Serotype-specific antigens (SPAs) of $A$. actinomycetemcomitans are polysaccharides consisting of 6-deoxyhexoses (Amano et al., 1989; Shibuya et al., 1991). SPA of $A$. actinomycetemcomitans serotype b is a

* Author for correspondence. Tel. 03-3444-2181; fax 03-3446-6286.

Abbreviations: SPA, serotype-specific antigen; THY broth, ToddHewitt broth supplemented with $1 \%(w / v)$ yeast extract; PBS, phosphate-buffered saline; PBST, PBS containing $0.05 \%(\mathrm{v} / \mathrm{v})$ Tween $20 ; \mathrm{mAb}$, monoclonal antibody. polymer consisting of a disaccharide repeating unit, $\rightarrow 3$ )$\alpha$-D-fucopyranosyl- $(1 \rightarrow 2)-\beta$-L-rhamnopyranosyl- $(1 \rightarrow$ (Amano et al., 1989). Patients with localized juvenile periodontitis have a high level of antibodies to SPA of $A$. actinomycetemcomitans serotype b (Ebersole et al., 1983; Califano et al., 1989; Sims et al., 1991). The ability of SPA from serotype $b$ to induce the release of interleukin1 by murine macrophages is higher than that of SPAs from serotypes a and c (Takahashi et al., 1991). However, the periodontopathic mechanism of SPA of serotype $b$ is poorly understood.

Tn916, which encodes tetracycline resistance $\left(\mathrm{Tc}^{r}\right)$, is a conjugative transposon on the chromosome of Enterococcus faecalis DS16 (Gawron-Burke \& Clewell, 1982; Clewell, 1986). The transposon is inserted into several different sites on the chromosomes of Ent. faecalis (Gawron-Burke \& Clewell, 1982), Streptococcus sanguis (Cawron-Burke \& Clewell, 1984), Streptococcus mutans (Procino et al., 1988; Caufield et al., 1990), Streptococcus 
pneumoniae (Watson \& Musher, 1990), Haemophilus influenzae (Kauc \& Goodgal, 1989) and Haemophilus parainfluenzae (Kauc \& Goodgal, 1989). The insertion of Tn916 into the bacterial chromosome has been reported to be useful for mutagenesis (Procino et al., 1988; Caufield et al., 1990; Watson \& Musher, 1990). In this study, SPA-defective mutants of serotype b A. actinomycetemcomitans were constructed by $\operatorname{Tn} 916$ insertion.

\section{Methods}

Bacterial strains. A. actinomycetemcomitans strains ATCC 29523 (serotype a), Y4 (serotype b) and NCTC 9710 (serotype c) were obtained from Y. Murayama (Okayama University, Okayama, Japan), Y. Yamamoto (Sunstar Corp., Osaka, Japan) and the National Collection of Type Cultures (London, UK), respectively. These strains were grown in Todd-Hewitt broth (Difco) supplemented with $1 \%(\mathrm{w} / \mathrm{v})$ yeast extract (THY broth) at $37^{\circ} \mathrm{C}$ in a $5 \% \mathrm{CO}_{2}$ atmosphere. Escherichia coli strain K235 was kindly provided by J. R. McGhee, University of Alabama at Birmingham, Al, USA, and grown aerobically in Trypticase soy broth (BBL) at $37^{\circ} \mathrm{C}$. E. coli DH1 (FrecAl endA 1 gyrA96 thi- 1 hsdR17 supE44) containing plasmid pAM 120 (pGL101::Tn916) was kindly supplied by D. B. Clewell, University of Michigan, Ann Arbor, MI, USA, and grown aerobically in LB broth (Lennox, 1955) containing ampicillin $\left(25 \mu \mathrm{g} \mathrm{ml}^{-1}\right)$ and tetracycline $\left(6 \mu \mathrm{g} \mathrm{ml}^{-1}\right)$. Transformant strains of $A$. actinomycetemcomitans were grown in THY broth containing tetracycline $\left(2 \mu \mathrm{g} \mathrm{ml}^{-1}\right)$.

Preparation of antigens. Lyophilized cell suspensions $\left(10 \mathrm{mg} \mathrm{ml}^{-1}\right)$ of A. actinomycetemcomitans strains in phosphate-buffered saline $(0 \cdot 15 \mathrm{M}$ $\mathrm{NaCl}, 0.01 \mathrm{M}$-sodium phosphate, $\mathrm{pH} 7.2$; PBS) were autoclaved at $120^{\circ} \mathrm{C}$ for $15 \mathrm{~min}$, and centrifuged at $1600 \mathrm{~g}$ at $4^{\circ} \mathrm{C}$. After centrifugation, the supernatants were collected and used as autoclaved extract. Phenol/water extracts from $A$. actinomycetemcomitans were prepared from cell suspensions $\left(10 \mathrm{mg} \mathrm{ml}^{-1}\right)$ by the modification by Inzana (1983) of the method of Westphal \& Jann (1965). SPA was extracted from lyophilized cells of $\boldsymbol{A}$. actinomycetemcomitans Y4 by autoclaving (Amano et al., 1989). The extract was purified by chromatography on columns of DEAE-Sephadex A-25 (Pharmacia) and Sephacryl S-300 (Pharmacia) and lyophilized (Amano et al., 1989).

Preparation of antibodies. Antiserum against whole cells of $\boldsymbol{A}$. actinomycetemcomitans $\mathrm{Y} 4$ was prepared in a rabbit by intravenous injections of formalin-killed whole cells. A monoclonal antibody (mAb) directed to SPA of $A$. actinomycetemcomitans Y4 (mAb S5) and one directed to lipopolysaccharide (LPS) of strain Y4 (mAb L2) were prepared and purified as described previously (Koga et al., 1990 b).

Construction and isolation of SPA-defective mutants. Plasmid pAM120 was isolated from $E$. col $i \mathrm{DH} l$ containing the plasmid as described by Sambrook et al. (1989). The plasmid preparation was purified twice by $\mathrm{CsCl} /$ ethidium bromide gradient centrifugation (Sambrook et al., 1989). A. actinomycetemcomitans Y4 was grown overnight in THY broth. The overnight culture $(0.5 \mathrm{ml})$ was diluted into $5 \mathrm{ml}$ fresh THY broth, and incubated at $37^{\circ} \mathrm{C}$ in a $5 \%(v / v) \mathrm{CO}_{2}$ atmosphere for about $4 \mathrm{~h}$ until an $\mathrm{OD}_{550}$ of $0.1-0.2$ was attained. Samples $(0.2 \mathrm{ml})$ were transferred to sterile glass culture tubes, and $1 \mu \mathrm{g}$ of pAM 120 DNA was added. After mixing gently, the mixtures were diluted with $1 \mathrm{ml}$ fresh THY broth and allowed to stand at $37^{\circ} \mathrm{C}$ in a $5 \% \mathrm{CO}_{2}$ atmosphere for $4 \mathrm{~h}$. The cultures were then diluted with PBS, plated on THY agar containing tetracycline $\left(2 \mu \mathrm{g} \mathrm{ml}^{-1}\right)$, and incubated at $37^{\circ} \mathrm{C}$ for $3 \mathrm{~d}$ Sterile nitrocellulose membrane filters were placed on colonies on the agar at $37^{\circ} \mathrm{C}$ for $2 \mathrm{~h}$, washed with PBS, and blocked with $3 \%(\mathrm{w} / \mathrm{v})$ bovine serum albumin (BSA) for $1 \mathrm{~h}$. The filters were reacted with $\mathrm{mAb}$ S5 (at a $1: 400$ dilution in PBS) at $25^{\circ} \mathrm{C}$ for $1 \mathrm{~h}$, and washed with PBS. The antibody bound to the immobilized antigens was detected by a solid-phase immunoassay with horseradish-peroxidase-conjugated goat anti-mouse immunoglobulin $\mathrm{G}$ (at a 1:1000 dilution in PBS; Cappel) (Koga et al., 1986). Clones that failed to react with mAb S5 were isolated as SPA-defective mutants.

Southern hybridization. Cellular DNA from A. actinomycetemcomitans was prepared as described by Okahashi et al. (1989) and digested with HindIII, EcoRI, or HindIII and SacI. The DNA fragments were separated by $0.7 \%(\mathrm{w} / \mathrm{v})$ agarose gel electrophoresis, and transferred to nylon membranes (Okahashi et al., 1989). pAM120 DNA biotinylated with the PhotoGene Nucleic Acid Detection System (Bethesda Research Laboratories) was used as a probe. Hybridization on nylon membranes was performed with $50 \%(\mathrm{v} / \mathrm{v})$ formamide at $42{ }^{\circ} \mathrm{C}$ (Okahashi et al., 1989).

Immunological procedures. Enzyme-linked immunosorbent assay (ELISA) was performed as described by Koga et al. $(1990 \mathrm{~b})$. In brief, whole cells $\left(0.1 \mathrm{mg} \mathrm{ml} \mathrm{ml}^{-1}\right)$ in $50 \mathrm{mM}$-carbonate/bicarbonate buffer (pH 9.6) were added to the wells of flat-bottomed polystyrene microtitre plates $(100 \mu \mathrm{l}$ each). After centrifuging the plates, $0.5 \%(\mathrm{v} / \mathrm{v})$ glutaraldehyde solution $(100 \mu \mathrm{l})$ was added to each well, and incubated for $15 \mathrm{~min}$ at room temperature. The plates were washed three times with PBS containing 0.05\% (v/v) Tween 20 (PBST). After a final wash, $1 \%(w / v)$ BSA in PBST (PBST-BSA) was added (100 $\mu$ l per well), and the plates were incubated at $25^{\circ} \mathrm{C}$ for $1 \mathrm{~h}$. Excess BSA was removed by three washes with PBST, and then serial twofold dilutions of $\mathrm{mAb}$ S5 or mAb L2 were added ( $100 \mu$ l per well). After incubation for $1 \mathrm{~h}$ at $25^{\circ} \mathrm{C}$, unbound antibodies were washed out with PBST and alkalinephosphatase-conjugated goat anti-mouse immunoglobulin $\mathrm{G}$ (Zymed) at a $1: 1000$ dilution in PBST-BSA was added $(100 \mu \mathrm{l}$ per well). The plates were incubated at $25^{\circ} \mathrm{C}$ for $1 \mathrm{~h}$, washed with PBST, and $p$ nitrophenyl phosphate $\left(1 \mathrm{mg} \mathrm{ml}{ }^{-1}\right)$ dissolved in diethanolamine buffer ( $\mathrm{pH} 9.6$ ) containing $0.02 \%\left(\mathrm{w} / \mathrm{v}\right.$ ) sodium azide and $0.5 \mathrm{mM}-\mathrm{MgCl}_{2}$ was then added $\left(100 \mu \mathrm{l}\right.$ per well). After incubation at $37^{\circ} \mathrm{C}$ for $1 \mathrm{~h}$, the $A_{405}$ was measured.

For Western blot analysis, the autoclaved extract or phenol/water extract from $A$. actinomycetemcomitans was mixed with an equal volume of $0.2 \mathrm{M}$-Tris/ $\mathrm{HCl}$ buffer ( $\mathrm{pH} 6.8$ ) containing $2 \%(\mathrm{w} / \mathrm{v}) \mathrm{SDS}, 4 \%$ (v/v) 2-mercaptoethanol, $0.4 \mathrm{~mm}$-EDTA, and heated at $100{ }^{\circ} \mathrm{C}$ for 5 $\mathrm{min}$. The mixture $(20 \mu \mathrm{l})$ was electrophoresed at $25 \mathrm{~mA}$ per gel at room temperature for $1.5 \mathrm{~h}$ using a $12.5 \%(\mathrm{w} / \mathrm{v})$ resolving and a $3 \%(\mathrm{w} / \mathrm{v})$ stacking gel $(90 \times 80 \times 1 \mathrm{~mm})$ containing $0.1 \%(\mathrm{w} / \mathrm{v})$ SDS, and transferred to a nitrocellulose sheet by the method of Towbin et al. (1979). After blocking with PBST-BSA, the sheet was treated with mAb S5 or mAb L2 at a 1:400 dilution in PBST. The antibody, bound to the immobilized replica antigens on the sheet, was detected with horseradish-peroxidase-conjugated goat anti-mouse immunoglobulin $\mathrm{G}$ (E.Y Laboratories) at a 1:400 dilution in PBST. Low-range prestained SDS-polyacrylamide gel electrophoresis standards (BioRad) were used as standards in Western blotting. Immunodiffusion was performed in $1 \%(w / v)$ Noble agar (Difco) in PBS.

Hydrophobicity. Cells of $A$. actinomycetemcomitans were suspended in PUM buffer (Rosenberg et al., 1980) to an OD ${ }_{550}$ of 0.6. Samples (3 ml) were placed in test tubes, and hexadecane $(300 \mu \mathrm{l})$ was added. The tubes were then vortex-mixed for $1 \mathrm{~min}$ and allowed to stand until the phases separated. The $\mathrm{OD}_{550}$ of the lower, aqueous phase was measured. Adsorption was calculated as the percentage loss in $\mathrm{OD}_{550}$ relative to that of the initial cell suspension (Koga et al., 1990a).

Sugar composition. The autoclaved extract $(5 \mathrm{mg})$ was hydrolysed with $400 \mu \mathrm{l}$ of $2 \mathrm{M}-\mathrm{HCl}$ at $100^{\circ} \mathrm{C}$ for $5 \mathrm{~h}$. The hydrolysate was dried by evaporation, and suspended in $100 \mu \mathrm{l}$ distilled water containing xylose 
$\left(30 \mu \mathrm{g} \mathrm{ml}^{-1}\right)$ as an internal standard. Sugar composition in the hydrolysate was analysed with a high-performance liquid chromatograph (model LC-4A; Shimadzu) equipped with a postcolumn labelling system for reducing sugars and an anion-exchange column (Shimpack ISA-07; Shimadzu) (Amano et al., 1989).

\section{Results}

\section{Construction and characterization of SPA-defective mutants}

To define the frequency of normally occurring spontaneous SPA-defective variants, we screened about 1500 colonies of $A$. actinomycetemcomitans Y4. However, all colonies strongly reacted with a mouse $\mathrm{mAb}$ to SPA of strain Y4 (mAb S5) in colony immunoblotting. To construct SPA-defective mutants, plasmid pAM120 containing transposon $\operatorname{Tn} 916$ was used to $\operatorname{transform} A$. actinomycetemcomitans Y4. The frequency of transformation was about $2 \times 10^{-}$transformants $\left(\mathrm{Tc}^{\mathrm{r}}\right)$ per viable cell. In colony immunoblotting, 11 clones among 1000 $\mathrm{Tc}^{\mathrm{r}}$ transformants gave negative or a very weak reaction with $\mathrm{mAb}$ S5, and were isolated as SPA-defective mutants. Reactivity of $\mathrm{mAb} \mathrm{S} 5$ and $\mathrm{mAb}$ L2 against whole cells of these clones was determined by ELISA. Two clones (strains ST1 and ST2) lacked reactivity with mAb S5, and 9 clones (strains ST 3 to ST11) reacted very weakly with it (Table 1). mAb S5 did not react with whole cells of $A$. actinomycetemcomitans strains ATCC 29523 (serotype a) and NCTC 9710 (serotype c), or E. coli K235. mAb L2 reacted with whole cells of all strains of $A$. actinomycetemcomitans used in this study, but not with those of $E$. coli $\mathrm{K} 235$ (Table 1). This mAb reacted more
Table 1. Reactivity of $m A b S 5$ and $m A b$ L2 against whole cells of A. actinomycetemcomitans and $E$. coli

\begin{tabular}{|c|c|c|}
\hline \multirow[b]{2}{*}{ Strain (serotype) } & \multicolumn{2}{|c|}{ ELISA titre $\left(A_{405}\right)^{*}$} \\
\hline & $\mathrm{mAb} S 5$ & $\mathrm{mAb} \mathrm{L2}$ \\
\hline \multicolumn{3}{|c|}{ A. actinomycetemcomitans } \\
\hline Y4 (b) & $1 \cdot 19$ & $1 \cdot 10$ \\
\hline ST1 & 0.03 & 2.76 \\
\hline ST2 & 0.03 & $2 \cdot 62$ \\
\hline ST3 & $0 \cdot 19$ & $2 \cdot 63$ \\
\hline ST4 & $0 \cdot 15$ & $2 \cdot 82$ \\
\hline ST5 & $0 \cdot 20$ & $2 \cdot 47$ \\
\hline ST6 & $0 \cdot 12$ & $2 \cdot 67$ \\
\hline ST7 & $0 \cdot 24$ & $2 \cdot 71$ \\
\hline ST8 & 0.21 & $2 \cdot 70$ \\
\hline ST9 & 0.26 & $2 \cdot 56$ \\
\hline ST10 & $0 \cdot 26$ & $2 \cdot 53$ \\
\hline ST11 & $0 \cdot 24$ & 2.68 \\
\hline ATCC 29523 (a) & 0.06 & $0 \cdot 67$ \\
\hline NCTC 9710 (c) & 0.02 & $0 \cdot 32$ \\
\hline \multicolumn{3}{|l|}{ E.coli } \\
\hline K235 & 0.03 & 0.06 \\
\hline
\end{tabular}

* Whole cells $(10 \mu \mathrm{g})$ were allowed to react with mAb S5 $(1: 32000$ dilution) or MAb L2 (1:128000 dilution). Each value represents the mean of triplicate assays.

strongly with whole cells of SPA-defective mutants than with those of the parent strain $\mathrm{Y} 4$, perhaps due to the exposure of LPS on their cell surfaces by the loss of SPA.

Immunodiffusion tests showed that $\mathrm{mAb}$ S5 or rabbit antiserum against whole cells of strain Y4 produced a fused precipitin band with purified SPA and autoclaved extract from $A$. actinomycetemcomitans Y4, but no precipitin band with autoclaved extracts from strains
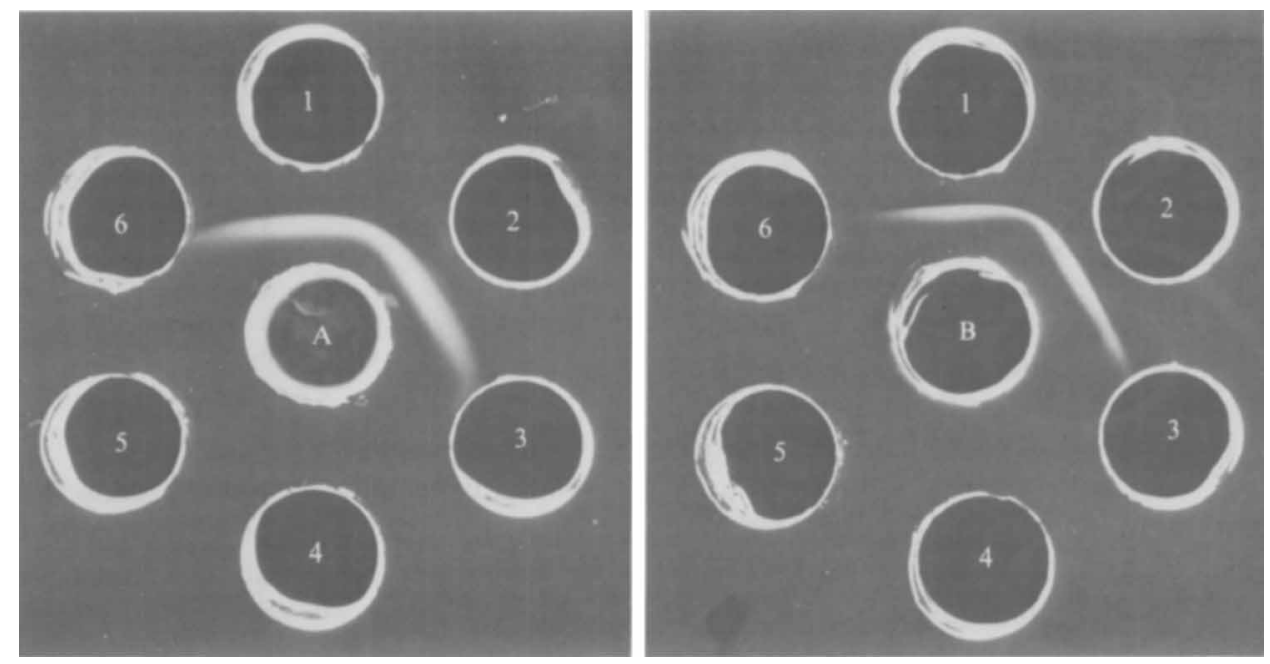

Fig. 1. Immunodiffusion of autoclaved extracts of A. actinomycetemcomitans strains against rabbit antiserum to whole cells of strain Y4 (A) and mAb S5 (B). Wells: 1, SPA purified from autoclaved extract of strain Y4; 2, autoclaved extract of strain Y4; 3, autoclaved extract of strain ST1; 4, autoclaved extract of strain ST2; 5, autoclaved extract of strain ST3; 6, autoclaved extract of strain ST5. 


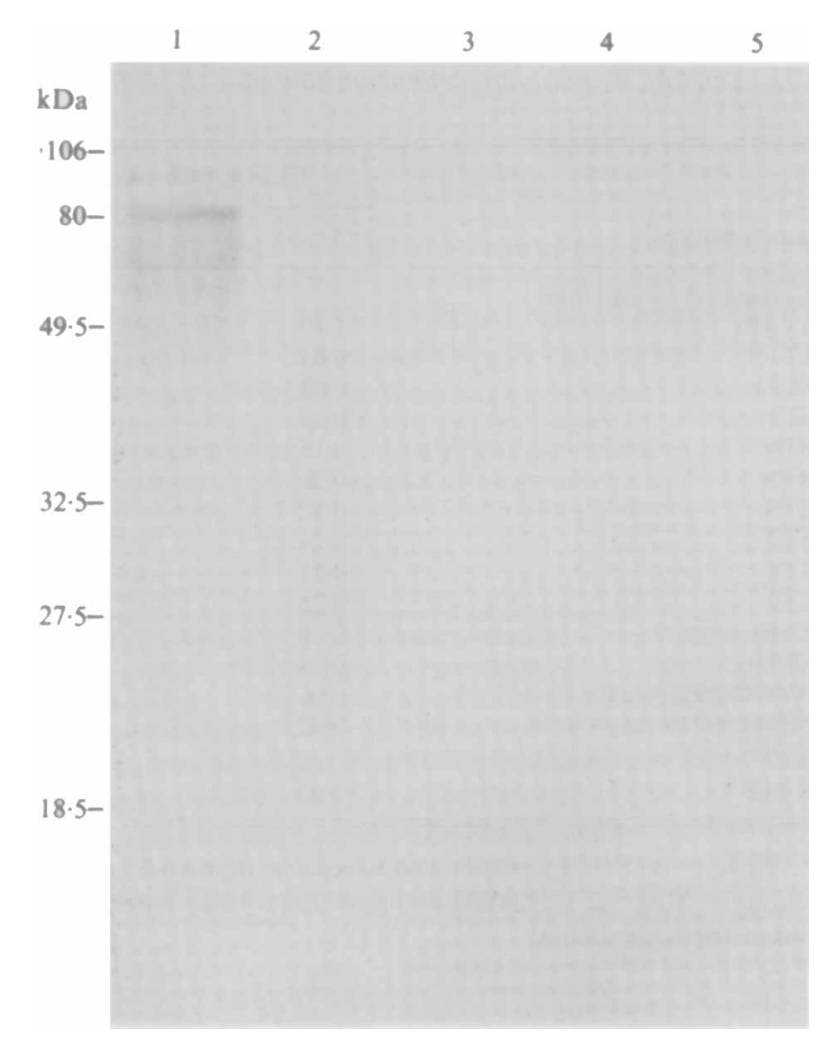

Fig. 2. Western blot analysis of autoclaved extracts of A. actinomycetemcomitans strains. Immobilized antigens transferred to a nitrocellulose sheet by an electrophoretic blotting procedure were allowed to react with $\mathrm{mAb}$ S5. The antibody was detected by solid-phase immunoassay with horseradish-peroxidase-conjugated goat anti-mouse IgG. Lanes: 1, strain Y4; 2, strain ST 1; 3, strain ST2; 4, strain ST3; 5 , strain ST5.

ST1, ST2, ST3 and ST5 (Fig. 1). Autoclaved extracts and phenol/water extracts from A. actinomycetemcomitans strains were analysed by Western blotting using mAb S5 and $\mathrm{mAb} L 2$, respectively. In the autoclaved extract from strain $\mathrm{Y} 4$, multiple high-molecular-mass bands reacted with $\mathrm{mAb}$ S5, but the autoclaved extracts from strains ST1, ST2, ST3 and ST5 did not react with this $\mathrm{mAb}$ (Fig. 2). In the phenol/water extracts from all strains of $A$. actinomycetemcomitans used in this study, diffuse low-molecular-mass bands reacted with $\mathrm{mAb}$ L2 (Fig. 3). These results indicate that these SPA-defective mutants as well as the parent strain Y4 have the ability to produce LPS.

Sugar composition of autoclaved extracts from $\boldsymbol{A}$. actinomycetemcomitans strains was determined by highperformance liquid chromatography. Rhamnose, fucose, galactose, glucose, glucosamine and three other unidentified sugars were detected in the autoclaved extract from strain Y4 (Table 2). The hydrolysates of autoclaved extracts from strains ST1 and ST2 contained a trace

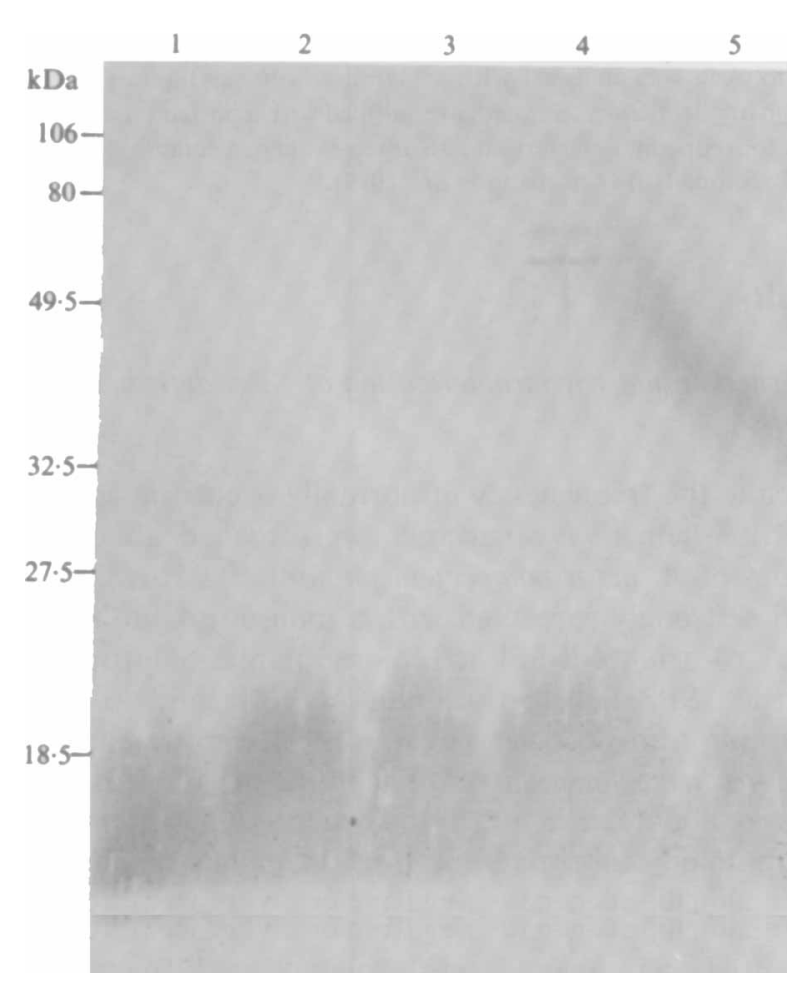

Fig. 3. Western blot analysis of phenol/water extracts of $A$. actinomycetemcomitans strains. Immobilized antigens on a nitrocellulose sheet were allowed to react with $\mathrm{mAb}$ L2. Lanes are as in Fig. 2.

Table 2. Sugar composition of autoclaved extracts from whole cells of $A$. actinomycetemcomitans strains

\begin{tabular}{lrrrrr}
\hline \hline & \multicolumn{5}{c}{ Content $(\mu \mathrm{g}$ per mg of whole cells)* } \\
\cline { 2 - 6 } Strain & Rha & \multicolumn{1}{c}{ Fuc } & Glc & Gal & GlcN \\
\hline Y4 & 0.13 & 0.13 & 0.65 & 0.54 & 0.36 \\
ST1 & $\mathbf{0 . 0 2}$ & $<\mathbf{0 . 0 1}$ & 0.54 & 0.43 & 0.30 \\
ST2 & $\mathbf{0 . 0 2}$ & $<\mathbf{0 . 0 1}$ & 0.55 & 0.36 & 0.19 \\
ST3 & $<\mathbf{0 . 0 1}$ & $\mathbf{0 . 0 4}$ & 0.58 & 0.31 & 0.24 \\
ST5 & $<0.01$ & $\mathbf{0 . 0 4}$ & 0.60 & 0.30 & 0.40 \\
\hline \hline
\end{tabular}

* Each value represents the mean for four assays. Three other unidentified sugars were detected by high-performance liquid chromatography, but their contents in strains ST1, ST2, ST3 and ST5 were almost the same as those in strain Y4.

amount of rhamnose, but not fucose. Those of autoclaved extracts from strains ST3 and ST5 contained a trace amount of fucose, but not rhamnose. The autoclaved extracts from all the mutants contained galactose, glucose, glucosamine and three unidentified sugars.

Cell-surface hydrophobicity of $A$. actinomycetemcomitans strains was determined by their adsorption to hexadecane. The hydrophobicity of SPA-defective 


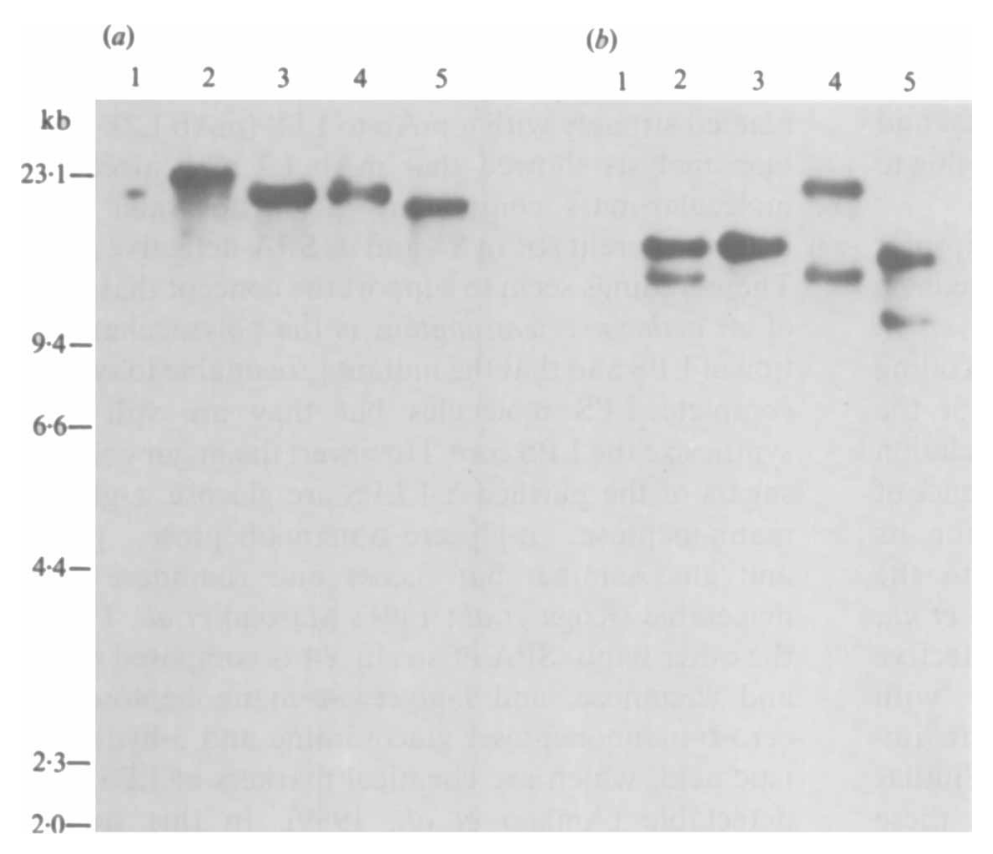

Fig. 4. Southern hybridization analysis of A. actinomycetemcomitans strains. Chromosomal DNAs from A. actinomycetemcomitans strains were digested with EcoRI (a) or HindIII (b). Hybridization was done with the biotinylated pAM 120 DNA probe at $42^{\circ} \mathrm{C}$ in $50 \%(\mathrm{v} / \mathrm{v})$ formamide. Lanes: 1 , strain $\mathrm{Y} 4 ; 2$, strain ST1; 3, strain ST2; 4, strain ST3; 5, strain ST5.
Table 3. Cell hydrophobicity of A. actinomycetemcomitans strains

\begin{tabular}{lc}
\hline \hline Strain & Hydrophobicity (\%) \\
\hline Y4 & $8.6 \pm 1.9$ \\
ST1 & $20.5 \pm 1.5$ \\
ST2 & $16.4 \pm 1.8$ \\
ST3 & $23.1 \pm 2.3$ \\
ST5 & $24.9 \pm 1.7$ \\
\hline \hline
\end{tabular}

* The bacterial suspension $(3 \mathrm{ml})$ was mixed with $0 \cdot 3 \mathrm{ml}$ hexadecane. Adsorption was calculated as the percentage loss in $\mathrm{OD}_{550}$ relative to that of the initial cell suspension. Each value represents the mean \pm standard deviation for five assays.

strains ST1, ST2, ST3 and ST5 was higher than that of the parent strain Y4 (Table 3).

\section{Analysis of Th916 insertions}

To confirm the integration of $\operatorname{Tn} 916$ into chromosomal DNA, we carried out Southern blot analysis of SPAdefective mutants by using biotinylated pAM120 DNA as a probe. The transposon contains one HindIII site and one SacI site, but no EcoRI site (Senghas et al., 1988). The biotinylated plasmid DNA hybridized with a 21$23 \mathrm{~kb} E c o$ RI fragment of chromosomal DNA from strains ST1, ST2, ST3 and ST5, but not with the chromosomal DNA from strain Y4 (Fig. 4a). The probe hybridized with two HindIII fragments of chromosomal
DNAs from these mutants (Fig. $4 b$ ). The sizes of hybridized HindIII fragments from strains ST1, ST2, ST3, and ST5 were 14 and $17 \mathrm{~kb}$, two $17 \mathrm{~kb}, 14$ and $22 \mathrm{~kb}$, and 10 and $16 \mathrm{~kb}$, respectively. To confirm the overlapping of hybridized HindIII fragments from strain ST2, chromosomal DNA from this strain was digested with both HindIII and SacI. The probe hybridized with three HindIII-SacI fragments of 1,9 and $17 \mathrm{~kb}$ (data not shown). These findings suggest a single insertion of Tn916 into different locations within the genome of $A$. actinomycetemcomitans.

\section{Discussion}

A. actinomycetemcomitans strain Y4 (serotype b) produces capsular-like SPA that is composed of $44 \% \mathrm{~L}$ rhamnose and $49 \% \mathrm{D}$-fucose in repeating disaccharide units, and a trace amount of fatty acid (Amano et al., 1989). In the present study, 11 SPA-defective mutants of A. actinomycetemcomitans $\mathrm{Y} 4$ were constructed by insertion of transposon Tn916. Southern blot analysis suggested that Tn916 was inserted into a variety of different sites on the chromosome. ELISA showed that whole cells of two mutant clones completely lacked reactivity with a mAb to SPA (mAb S5). Those of the other clones reacted very weakly with $\mathrm{mAb}$ S5, suggesting that in these clones Tn916 might have inserted into sites that regulate the expression of SPA or that these clones might produce an mAb S5-reactive antigen 
different from SPA. Autoclaved extracts from clones that reacted very weakly with $\mathrm{mAbS} 5$ in ELISA failed to react with this $\mathrm{mAb}$ in immunodiffusion tests and Western blot analysis. This discrepancy might be due to the difference in sensitivity among the assays.

Neisseria meningitidis serogroup B produces a capsular polysaccharide that is composed of $\alpha-2,8$-linked $N$ acetylneuraminic acid (Jennings, 1990). Frosch et al. (1989) have recently cloned the gene complex encoding all determinants of the biosynthetic pathway of the capsule of the organism. Using transposon and deletion mutagenesis, they presented evidence for the existence of distinct genetic functions that are essential for its synthesis and transport from the cytoplasm to the periplasm and further to the cell surface (Frosch et al., 1989). No autoclaved extracts from SPA-defective mutants of $A$. actinomycetemcomitans reacted with monoclonal and polyclonal antibodies to SPA in immunodiffusion tests and Western blot analysis. Similar results were obtained with sonic extracts from these mutants (data not shown). These findings indicate that the lack of SPA in these mutants is not due to the inactivation of the gene for the transport of the polysaccharide.

Polysaccharide capsules of various organisms, such as Bacteroides fragilis (Kasper et al., 1984), $H$. influenzae (Moxon \& Vaughn, 1981), Vibrio vulnificus (Wright et al., 1990 ) and S. pneumoniae (Watson \& Musher, 1990), have been reported to be important for their pathogenicity. Takahashi et al. (1991) reported that SPA of $A$. actinomycetemcomitans serotype $\mathrm{b}$ strongly induces the release of interleukin-1 by murine macrophages. This finding suggests that the SPA of A. actinomycetemcomitans may play a critical role in the pathogenesis of the organism.

The role of cell-surface hydrophobicity in mediating bacterial adherence to tooth surfaces and host cell surfaces has recently received increased attention (Rosenberg \& Doyle, 1990). Most capsular polysaccharides are hydrophilic (Moxon \& Kroll, 1990). The presence of capsular polysaccharide has been reported to reduce the cell hydrophobicity of Pasteurella multocida, Streptococcus pyogenes, Acinetobacter calcoaceticus, Klebsiella pneumoniae and Staphylococcus aureus (Rosenberg \& Doyle, 1990). SPA-defective mutants of A. actinomycetemcomitans were more hydrophobic than the parent strain. Hydrophilic SPA of $A$. actinomycetemcomitans may interfere with the hydrophobic interaction between the organism and the host cell. However, the possibility also exists that the SPA of $A$. actinomycetemcomitans might participate in the lectin-like interaction between the organism and the host cell.

SPA of $A$. actinomycetemcomitans serotype $\mathrm{b}$ was recently reported to be a portion of the $\mathrm{O}$-polysaccharide of LPS (Page et al., 1991; Wilson \& Schifferle, 1991). In this study, whole cells of all SPA-defective mutants reacted strongly with a mAb to LPS (mAb L2). Western blot analysis showed that $\mathrm{mAb}$ L2 recognized a lowmolecular-mass component in phenol/water extracts from the parent strain Y4 and its SPA-defective mutants. These findings seem to support the concept that the SPA of $A$. actinomycetemcomitans is the polysaccharide portion of LPS and that the mutants are unable to synthesize complete LPS molecules but they are still able to synthesize the LPS core. However, the major component sugars of the purified Y4 LPS are glucose, L-glycero-Dmannoheptose, D-glycero-D-mannoheptose, galactose and glucosamine, but fucose and rhamnose are not detectable (Koga et al., 1991; Masoud et al., 1991). On the other hand, SPA of strain Y4 is composed of fucose and rhamnose, and L-glycero-D-mannoheptose, D-glycero-D-mannoheptose, glucosamine and 3-hydroxymyristic acid, which are chemical markers of LPS, are not detectable (Amano et al., 1989). In this study, the rhamnose and fucose contents of autoclaved extracts from the mutants, as compared with the autoclaved extract from strain Y4, were very low. However, the hydrolysates of autoclaved extracts from all SPAdefective mutants contained large amounts of glucose, galactose and glucosamine. In immunodiffusion assays, the two precipitin lines that formed when rabbit antiserum against whole cells of strain Y4 was reacted with purified Y4 SPA and with purified Y4 LPS crossed completely (unpublished data). Further work is needed to determine whether SPA of A. actinomycetemcomitans serotype $\mathrm{b}$ is related to LPS.

The Tn916-induced mutant clones described here should prove very useful for clarifying the role of SPA of A. actinomycetemcomitans in the virulence of the organism and locating the genetic determinants for the biosynthesis of SPA. In addition, fragments containing the transposon in the chromosomes of SPA-defective mutants will be useful for cloning the gene complex responsible for the synthesis of SPA and the regulation of expression of the polysaccharide.

This work was supported in part by a grant-in-aid for scientific research (02454479) from the Ministry of Education, Science Research and Culture of Japan and a research grant from the Japan Foundation for Aging and Health.

\section{References}

Amano, K., Nishihara, T., Shibuya, N., Noguchi, T. \& Koga, T. (1989). Immunochemical and structural characterization of a serotype-specific polysaccharide antigen from Actinobacillus actinomycetemcomitans Y4 (serotype b). Infection and Immunity 57, 29422946.

Asikainen, S., lai, C.-H., Alaluusua, S. \& Slots, J. (1991). Distribution of Actinobacillus actinomycetemcomitans serotypes in 
periodontal health and disease. Oral Microbiology and Immunology 6, 115-118

Califano, J. V., Schenkein, H. A. \& Tew, J. G. (1989). Immunodominant antigen of Actinobacillus actinomycetemcomitans $\mathrm{Y} 4$ in high-responder patients. Infection and Immunity 57, 1582-1589.

Caufield, P. W., Shah, G. R. \& Hollingshead, S. K. (1990). Use of transposon $\operatorname{Tn} 916$ to inactivate and isolate a mutacin-associated gene from Streptococcus mutans. Infection and Immunity 58, 41264135 .

Clewell, D. B. (1986). Conjugative transposons and the dissemination of antibiotic resistance in streptococci. Annual Review of Microbiology 40, 635-659.

Ebersole, J. L., Taubman, M. A., Smith, D. J., Hammond, B. F. \& FrEY, D. E. (1983). Human immune responses to oral microorganisms. II. Serum antibody responses to antigens from Actinobacillus actinomycetemcomitans and the correlation with localized juvenile periodontitis. Journal of Clinical Immunology 3, 321-331.

Frosch, M., WeIsgerber, C. \& MEyer, T. F. (1989). Molecular characterization and expression in Escherichia coli of the gene complex encoding the polysaccharide capsule of Neisseria meningitidis group B. Proceedings of the National Academy of Sciences of the United States of America 86, 1669-1673.

Gawron-Burke, C. \& Clewell, D. B. (1982). A transposon in Streptococcus faecalis with fertility properties. Nature, London $\mathbf{3 0 0}$, 281-284.

Gawron-Burke, C. \& Clewell, D. B. (1984). Regeneration of insertionally inactivated streptococcal DNA fragments after excision of transposon $\mathrm{Tn} 916$ in Escherichia coli: strategy for targeting and cloning of genes from gram-positive bacteria. Journal of Bacteriology 159, 214-221.

INZANA, T. J. (1983). Electrophoretic heterogeneity and interstrain variation of the lipopolysaccharide of Haemophilus influenzae. Journal of Infectious Diseases 148, 492-499.

JenNings, H. J. (1990). Capsular polysaccharides as vaccine candidates. Current Topics in Microbiology and Immunology 150, 97-127.

KaSPER, D. L., LindBerg, A. A., Weintraub, A., ONDERDonK, A. B \& LöNNGREN, J. (1984). Capsular polysaccharides and lipopolysaccharides from two strains of Bacteroides fragilis. Reviews of Infectious Diseases 6, S25-S29.

KAUC, L. \& GOODGAL, S. H. (1989). Introduction of transposon Tn916 DNA into Haemophilus influenzae and Haemophilus parainfluenzae. Journal of Bacteriology 171, 6625-6628.

Koga, T., Asakawa, H., OKahashi, N. \& Hamada, S. (1986). Sucrosedependent cell surface and cariogenicity of serotype $c$ Streptococcus mutans. Journal of General Microbiology 132, 2873-2883.

Koga, T., Okahashi, N., Takahashi, I., Kanamoto, T., Asakawa, H. \& IWAKI, M. (1990a). Surface hydrophobicity, adherence, and aggregation of cell surface protein antigen mutants of Streptococcus mutans serotype c. Infection and Immunity 58, 289-296.

Koga, T., Senpuku, H., Nakashima, K., Ishihara, Y. \& Nishihara, T. $(1990 \mathrm{~b})$. Monoclonal antibody-coated latex agglutination assay for identification of Actinobacillus actinomycetemcomitans. Zentralblatt für Bacteriologie 274, 91-99.

Koga, T., Nishihara, T., Amano, K., Takahashi, T., Nakashima, K., IsHIHARA, Y. \& SHIBUYA, N. (1991). Chemical and biological properties of cell-surface components of Actinobacillus actinomycetemcomitans. In Periodontal Disease: Pathogens \& Host Immune Responses, pp. 117-127. Edited by S. Hamada, S. C. Holt \& J. R. McGhee. Tokyo: Quintessence Publishing $\mathrm{Co}$.

LENNOX, E. S. (1955). Transduction of linked genetic characters of the host by bacteriophage P1. Virology 1, 190-206.

Masoud, H., Weintraub, S. T., Wang, R., Cotter, R. \& Holt, S. C (1991). Investigation of the structure of lipid A from Actinobacillus actinomycetemcomitans strain $\mathrm{Y} 4$ and human clinical isolate $\mathrm{PO}$ 1021-7. European Journal of Biochemistry 200, 775-779.

Moxon, E. R. \& KRoll, J. S. (1990). The role of bacterial polysaccharide capsules as virulence factors. Current Topics in Microbiology and Immunology 150, 65-85.

Moxon, E. R. \& Vaughn, K. A. (1981). The type b capsular polysaccharide as a virulence determinant of Haemophilus influen$z a e$ : studies using clinical isolates and laboratory transformants. Journal of Infectious Diseases 143, 517-524.

Okahashi, N., Sasakawa, C., Yoshikawa, M., Hamada, S. \& Koga,
T. (1989). Cloning of a surface protein antigen gene from serotype $c$ Streptococcus mutans. Molecular Microbiology 3, 221-228.

Page, R. C., Sims, T. J., Engel, L. D., Moncla, B. J., Bainbridge, B., Stray, J. \& Darveau, R. P. (1991). The immunodominant outer membrane antigen of Actinobacillus actinomycetemcomitans is located in the serotype-specific high-molecular-mass carbohydrate moiety of lipopolysaccharide. Infection and Immunity 59, 3451-3462.

Procino, J. K., Marri, L., Shockman, G. D. \& Daneo-Moore, L. (1988). Tn916 insertional inactivation of multiple genes on the chromosome of Streptococcus mutans GS-5. Infection and Immunity 56, 2866-2870

RosenberG, M. \& DOYle, R. J. (1990). Microbial cell surface hydrophobicity: history, measurement, and significance. In Microbial Cell Surface Hydrophobicity, pp. 1-37. Edited by R. J. Doyle \& M. Rosenberg. Washington, DC: American Society for Microbiology.

Rosenberg, M., Gutnick, D. \& Rosenberg, E. (1980). Adherence of bacteria to hydrocarbons: a simple method for measuring cellsurface hydrophobicity. FEMS Microbiology Letters 9, 29-33.

Sambrook, J., Fritsch, E. F. \& Maniatis, T. (1989). Molecular Cloning: a Laboratory Manual, 2nd edn. Cold Spring Harbor, NY: Cold Spring Harbor Laboratory.

Senghas, E., Jones, J. M., Yamamoto, M., Gawron-Burke, C. \& ClewELl, D. B. (1988). Genetic organization of the bacterial conjugative transposon Tn916. Journal of Bacteriology 170, 245-249.

Shibuya, N., Amano, K., Azuma, J., Nishihara, T., Kitamura, Y., NoguchI, T. \& KogA, T. (1991). 6-Deoxy-D-talan and 6-deoxy-Ltalan: novel serotype-specific polysaccharide antigens from Actinobacillus actinomycetemcomitans. Journal of Biological Chemistry 266, 16318-16323.

Sims, T. J., Moncla, B. J., Darveau, R. P. \& Page, R. C. (1991). Antigens of Actinobacillus actinomycetemcomitans recognized by patients with juvenile periodontitis and periodontally normal subjects. Infection and Immunity 59, 913-924.

SLOTS, J. \& GENCO, R. J. (1984). Black-pigmented Bacteroides species, Capnocytophaga species, and Actinobacillus actinomycetemcomitans in human periodontal disease: virulence factors in colonization, survival, and tissue destruction. Journal of Dental Research 63, 412421

SLOTS, J. \& SCHONFELD, S. E. (1991). Actinobacillus actinomycetemcomitans in localized juvenile periodontitis. In Periodontal Disease: Pathogens \& Host Immune Responses, pp. 53-64. Edited by S. Hamada, S. C. Holt \& J. R. McGhee. Tokyo: Quintessence Publishing Co.

Takahashi, T., Nishihara, T., Ishihara, Y., Amano, K., ShibuYa, N., MORO, I. \& KogA, T. (1991). Murine macrophage interleukin-1 release by capsularlike serotype-specific polysaccharide antigens of Actinobacillus actinomycetemcomitans. Infection and Immunity 59, 18 23.

Tanner, A. C. R., Haffer, C., Bratthall, G. T., Visconti, R. A. \& SoCRANSKY, S. S. (1979). A study of the bacteria associated with advancing periodontitis in man. Journal of Clinical Periodontology 6 , 278-307.

Towbin, H., Staehelin, T. \& Gordon, J. (1979). Electrophoretic transfer of proteins from polyacrylamide gels to nitrocellulose sheets: procedure and some applications. Proceedings of the National Academy of Sciences of the United States of America 76, 4350-4354.

WATSON, D. A. \& MUSHER, D. M. (1990). Interruption of capsule production in Streptococcus pneumoniae serotype 3 by insertion of transposon Tn916. Infection and Immunity 58, 3135-3138.

WESTPHAL, O. \& JANN, K. (1965). Bacterial lipopolysaccharide. Extraction with phenol-water and further applications of the procedure. Methods in Carbohydrate Chemistry 5, 83-91.

WILSON, M. E. \& SCHIFFERLE, R. E. (1991). Evidence that the serotype $\mathrm{b}$ antigenic determinant of Actinobacillus actinomycetemcomitans Y4 residues in the polysaccharide moiety of lipopolysaccharide. Infection and Immunity 59, 1544-1551.

Wright, A. C., Simpson, L. M., Oliver, J. D. \& Morris, J. D. (1990). Phenotypic evaluation of acapsular transposon mutants of Vibrio vulnificus. Infection and Immunity 58, 1769-1773.

Zambon, J. J., Slots, J. \& Genco, R. J. (1983). Serology of oral Actinobacillus actinomycetemcomitans and serotype distribution in human periodontal disease. Infection and Immunity 41, 19-27. 